\title{
Brewing Efficacy of Non-Conventional Saccharomyces Non-Cerevisiae Yeasts
}

Authors: James Bruner ${ }^{1,2}$ (ORCiD: 0000-0003-3691-0711), Andrew Marcus ${ }^{1}$, Glen Fox ${ }^{1 *}$ (ORCiD: 0000-0001-7502-0637)

\section{Addresses:}

1. Food Science and Technology Department, University of California, 1 Shields Ave, Davis, CA, USA 95616

2. Creature Comforts Brewing Company, 271 W. Hancock Ave, Athens, GA, USA 30601

*Corresponding authors: gpfox@ucdavis.edu 


\begin{abstract}
Consumer demands for new sensory experiences have driven the research of unconventional yeasts in beer. While much research exists on the use of various common Saccharomyces cerevisiae strains as well as non-Saccharomyces yeasts, there exists a gap in knowledge regarding other non-cerevisiae Saccharomyces species in the fermentation of beer, outside that of $S$. pastorianus. Here, five distinct species of Saccharomyces from the UC Davis Phaff Yeast Culture Collection, as well as one interspecies hybrid from Fermentis, were chosen to ferment 40 L pilot scale beers. $S$. kudriavzevii, S. mikatae, S. paradoxus, $S$. bayanus, and $S$. uvarum yeasts were fermented in duplicate, with one fermenter in each pair receiving $10 \mathrm{~g} / \mathrm{L}$ dryhop during fermentation. Analytical measurements were made each day of fermentation and compared to controls of SafAle US-05 and SafLager W 34/70 for commercial brewing parameters of interest. Finished beers were also analyzed for aroma, taste, and mouthfeel to determine the flavor of each yeast as it pertains to brewing potential. All beers exhibited spicy characteristics, likely from the presence of phenols; dry-hopping increased fruit notes while also increasing perceived bitterness and astringency. All of the species in this study displayed great brewing potential, and might be an ideal addition to beer depending on a brewery's desire to experiment with flavor and willingness to bring a new yeast into their production environment.
\end{abstract}

Keywords: non-conventional yeasts, Saccharomyces, fermentation, beer, dry-hopping, brewing potential

\title{
A. Introduction
}

Increasingly, changing demands by beer drinkers in search of new sensory experiences are driving research into novel fermentations [1-4]. Much of this research has utilized nonSaccharomyces yeast strains [5-12], which can be attributed to the rise in popularity of mixed- 
fermentation beers [13-15]. This pursuit of distinctive aromas and flavors has similarly driven the increased use of non-cerevisiae Saccharomyces species in the alcoholic fermentation of all beverages [16-22]. While much of this work has been focused on wine fermentations, the most widely used non-cerevisiae species is $S$. pastorianus, which has been used the world over in the production of lager beers for centuries [20,23-26].

In addition to novel yeast-derived flavors, brewers are increasingly turning to dryhopping to enhance their consumers' sensory experience. Historically this procedure of adding hops (Humulus lupulus) cones to beer when fermentation is active or finished was performed to provide packaging and transport stability [27,28]. Relatively more recently with the rise of Craft Brewers, dry-hopping with pellets or advanced hop products [29] has become a common tactic used by brewers desiring to add interesting flavors and aromas to their beer [30].

All Saccharomyces yeast species that have been found to produce ethanol from carbohydrate sugar sources have been classified as part of the Saccharomyces sensu stricto (Sss) complex [31-33]. While the Sss currently contains ten distinct species, only eight have been linked to alcoholic beverage fermentation (Fig. 1). Use of S. cerevisiae and S. pastorianus have long been known for their use in alcoholic beverage production, but the Sss contains several nonconventional species. S. kudriavzevii, S. mikatae, S. paradoxus, S. bayanus, and S. uvarum that have already shown potential for alcoholic beverages, and have been identified in fermentations of wine, tepache, cider, chicha, palm wine, umqombothi, and other beverages [19,34-39]. Many of these fermented beverages, however, contain mixed cultures of yeasts and sometimes bacteria, in addition to naturally formed interspecies hybrids between two or more different Saccharomyces species $[24,40]$. To date, none of these species have been evaluated in 
monoculture fermentations in a beer brewing context, but their efficacy has been previously reviewed [41].

Fermentations

(beer, wine, etc.)

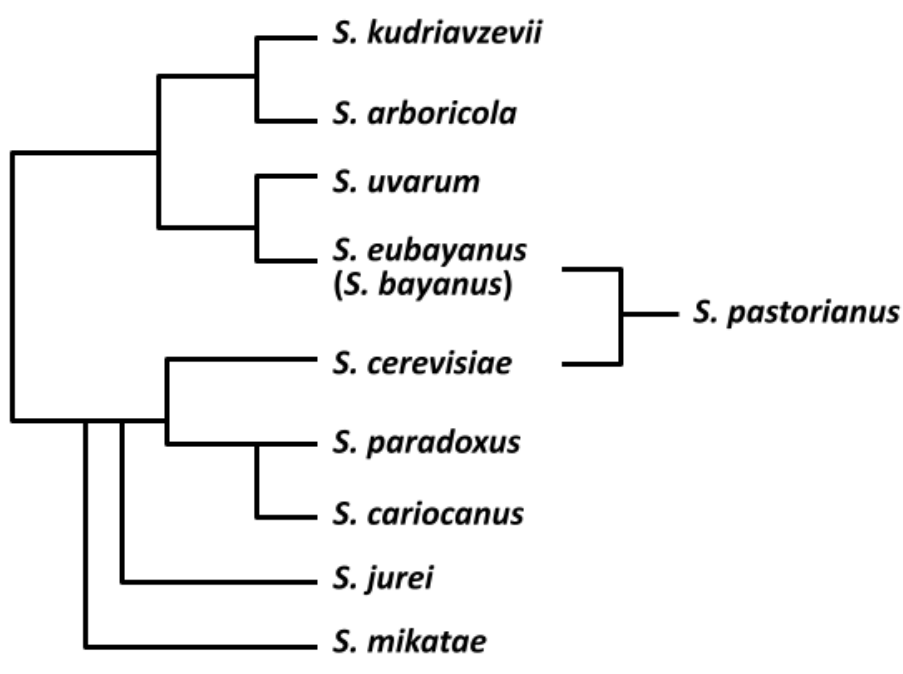

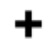
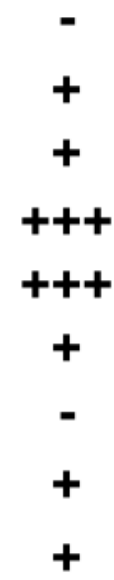

Figure 1. Sss phylogeny and extent of use in alcoholic beverage fermentations. Saccharomyces bayanus is listed in parenthesis to indicate it was derived from multiple hybridization events [42]. S. pastorianus is shown as a genetic hybrid of S. eubayanus and S. cerevisiae [21]. Use in fermented beverages is indicated with plus signs (+) for current commercial use, with $S$. cerevisiae and S. pastorianus exhibiting the most ubiquitous use in beer, and negative signs (-) for no known use. S. cariocanus is known to be harboring just four translocated chromosomes different than S. paradoxus [43]. S. jurei has very recently been proven to have brewing potential [44].

First isolated from oak trees of western Europe, S. kudriavzevii is a wild-type yeast that has been sequenced to contribute $23-96 \%$ of its genome to hybrids with $S$. cerevisiae $[16,19,45]$. While no commercial examples of its use in beer fermentation exist, S. kudriavzevii has been isolated from mixed-cultures of farmhouse ciders in France and draft beer systems in Germany to New Zealand [46,47]. Due to its propensity to hybridize, this yeast has even been found as part of the genetic makeup in Belgian Trappist ale strains from Chimay, Westmalle, and Orval [48]. S. kudriavzevii is a cryophilic species and is currently used to ferment wines at lower temperatures $\left(10^{\circ} \mathrm{C}\right.$ to $\left.15^{\circ} \mathrm{C}\right)$ in Europe and Australia [19,49]. Because it thrives at low 
temperatures and may have aromas similar to Belgian beers, $S$. kudriavzevii has potential for use in the production of hoppy lager beers in the brewing industry.

S. paradoxus has been found in African umqombothi [38] and white wine fermentations previously [50], but has only been studied for its beer brewing potential (at $15^{\circ} \mathrm{C}$ ) very recently, since the inception of this research [22]. S. paradoxus was one of the first species isolated as a member of the Sss outside of S. pastorianus and S. cerevisiae and is typically found in tree sap of Northeastern Europe [51]. Being a wild-type yeast species suggests $S$. paradoxus may produce interesting volatile aroma compounds at warmer $\left(18{ }^{\circ} \mathrm{C}\right.$ to $\left.24^{\circ} \mathrm{C}\right)$ ale temperatures [52]. Saccharomyces mikatae is a wild yeast that contributes to genetic hybrids from interspecies hybridization events with $S$. cerevisiae and S. paradoxus [53], and was first isolated from soil and decaying leaves in Japan [43]. S. mikatae was shown to form a biofilm on the surface of liquid media (pellicle) after twenty-five days at $20^{\circ} \mathrm{C}$, similar to wild-type strains [43]. It produced fruity, banana, floral, and sweet perfume aromas in white wine, and ferment slowly, perhaps all due to its diversion from the $S$. cerevisiae parent genome [54,55]. Both S. paradoxus and $S$. mikatae offer unique characteristics that might be of interest to craft brewers creating beer at ale fermentation temperatures.

Saccharomyces bayanus was previously thought to be the parent of the lager strain, $S$. pastorianus $[21,47,56]$, but the hybridization event that produced lager brewing yeast is now proven to have occurred between $S$. cerevisiae and S. eubayanus $[25,34,57,58]$. S. bayanus has been characterized as its own species within the $S s s$, but in order delineate it from $S$. eubayanus and $S$. uvarum, it is commonly referred to as $S$. bayanus var. bayanus [21,42]. Genetic analysis of organisms in beer fermentations have identified S. bayanus as part of blended cultures due to its chromosomal similarity to $S$. pastorianus [26], but it is most common as a solitary species in 
wine fermentations [58]. A close relative, Saccharomyces uvarum, was once was thought to be a variant of S. bayanus, but has since been confirmed as a distinct species [59]. S. uvarum has been found to be part of the mixed culture of spontaneously fermented wines [36], as well as an interspecies hybrid known in some Norwegian kveik strains [17]. Both S. bayanus and S. uvarum exhibit increased levels of isoamyl acetate in wine and brandy [60,61], and might contribute similar flavor to beer.

Some yeast suppliers are leveraging the power of interspecies hybrids to create distinctive sensory experiences, including a $S$. cerevisiae x $S$. bayanus hybrid produced by FermentisLeSaffre (Marcq-en-Baroeul, France, EU; fermentis.com/en/) known as SafCEno HDT18 [62]. This interspecies hybrid has been created through a LeSaffre R\&D program to select a yeast strain that exhibits increased expression of aromatic terpenes. New research has identified these terpene compounds as some of the most impactful on dry-hopped beer aroma [30,63] through biotransformation with glycosides and alcohols to produce unique aroma characteristics [64]. While this yeast was developed for wine fermentations, it may be of great interest to brewers making dry-hopped beers, and was therefore selected for this study.

While there is much research regarding the use of some of these species in a laboratory scale or wine fermentation, work remains for their efficacy and commercial use in the production of beer. Additionally, little to no sensorial analysis exists on the use of any of these Saccharomyces spp. in the fermentation of beer, most notably at ale fermentation temperatures $\left(18-20^{\circ} \mathrm{C}\right)$ or in dry-hopped beers. The aim of this study is to assess the brewing potential of the non-conventional non-cerevisiae Saccharomyces species outlined above by assessing fermentation kinetics and performance, yeast abundance and viability post-fermentation for serial re-pitching, as well as the flavor characteristics of the resultant beer. Beers in this study 
will be run as both dry-hopped and standard fermentations due to the pervasiveness of dryhopping in the American craft brewing industry. While the most widely used non-cerevisiae Saccharomyces species is S. pastorianus, it will not be discussed here as much research already exists on its brewing potential.

\section{B. Materials and Methods}

\section{a. Experimental Beers}

A total of eight all-malt pilot scale brews were performed on the $1.8 \mathrm{hL}$ Anheuser-Busch Research Pilot Brewery at the University of California, Davis. Brewing parameters, as well as the malt, hops, water chemistry, mashing regime, $\mathrm{pH}$, boiling parameters, and knockout temperatures followed the same method as outlined in previous research[65]. The experimental beer recipe was similar to an American Pale Ale or Session IPA, with a target original gravity of $10^{\circ} \mathrm{P}$, to yield a $4.2 \%(\mathrm{v} / \mathrm{v})$ alcohol beer under standard ale fermentation conditions. Wort from each of the eight brews was split evenly by volume between four $56 \mathrm{~L}$ fermenters, to fill each with approximately $40 \mathrm{~L}$ of cooled wort.

\section{b. Yeasts}

Saccharomyces yeasts sourced from the University of California, Davis, Phaff Yeast Culture Collection (phaffcollection.ucdavis.edu) included the type strains of S. kudriavzevii, S. mikatae, S. paradoxus, S. bayanus, and S. uvarum. Additionally, the control S. cerevisiae and $S$. pastorianus species and one S. cerevisiae x S. bayanus hybrid were provided by Fermentis (Table 1). Yeasts from the Phaff Collection were revived from cryogenic storage and streaked onto potato dextrose agar (PDA) plates and incubated for 2 days at $30{ }^{\circ} \mathrm{C}$ before being moved to room temperature storage until propagation. Yeasts from Fermentis were provided as an active dry yeast with the emulsifier E491 (sorbitan monostearate) and stored at $4{ }^{\circ} \mathrm{C}$ until propagation. 
Table 1. Non-conventional non-cerevisiae Saccharomyces and control yeasts used in the fermentations of the experimental beer. Yeasts were sourced from either the Phaff Yeast Culture Collection at the University of California, Davis (UCD), or from Fermentis LeSaffre of Marcq-en-Baroeul, France (Saf). Type strain as defined in MycoBank (mycobank.org), origin, isolation, flocculation, and attenuation, as defined in the scientific or product literature. SafAle US-05 and SafLager W 34/70 are included as controls.

\begin{tabular}{|c|c|c|c|c|c|c|}
\hline Scientific Name & Yeast Name & Type Strain & Isolated From & Geographic Origin & Flocculation & Attenuation \\
\hline Saccharomyces kudriavzevii & UCDFST 11-515 & NCYC 2889T & oak tree bark & Western Europe & Medium High & Moderate \\
\hline Saccharomyces paradoxus & UCDFST 01-161 & DBVPG 6411 & tree exudate & Northeast Europe & Medium & Moderate \\
\hline Saccharomyces mikatae & UCDFST $11-510$ & NCYC 2888T & soil & Japan & Medium & Moderate Low \\
\hline Saccharomyces bayanus & UCDFST 01-135 & CBS 380 & turbid beer & Italy & Medium & Moderate \\
\hline Saccharomyces uvarum & UCDFST $11-512$ & CBS 395 & fruit and seeds & Scandinavia & High & Moderate \\
\hline $\begin{array}{l}\text { Saccharomyces cerevisiae x Saccharomyces } \\
\text { bayanus }\end{array}$ & SafCEno HD T18 & $(\mathrm{R} \& \mathrm{D})^{*}$ & LeSaffre R\&D & France & Medium & High \\
\hline Saccharomyces cerevisiae & SafAle US- $05^{* *}$ & $*$ & $*$ & USA & Medium & $78-82 \%$ \\
\hline Saccharomyces pastorianus & SafLager W 34/70 & W 34/70 & Weihenstephan & Germany & High & $80-84 \%$ \\
\hline
\end{tabular}

* unknown **SafAle US-05 fermentations were done in biological triplicate. 
All yeast were propagated according to the same procedure to ensure consistency throughout this study. Due to time constraints with research brewing, only one yeast was chosen on which to perform three biological replicates to ferment from three separate brews: $S$. cerevisiae SafAle US-05. Yeasts were propagated in wort consisting of $10.0 \% \mathrm{w} / \mathrm{v}\left(10.0{ }^{\circ} \mathrm{P}\right.$, 1.040 Specific Gravity) dried pilsner malt extract (Briess CBW® Pilsen Light; Chilton, WI, USA) in deionized water with $20 \mathrm{ppm} \mathrm{CaCl}_{2}$ salts, targeting $5.2 \mathrm{pH}$, and $0.10 \%$ w/v yeast nutrient (Kerry Yeastex® 82; Beloit, WI, USA). Wort was boiled for ten minutes and sterilized via autoclave before being sterile filtered to remove protein and trub particulate. All transfers of yeast and wort were done in a laminar flow hood or positive pressure room. Yeast colonies were transferred from PDA plate or package of active dry yeast via sterile inoculation loop to propagation wort and propagated stepwise over the course of 11 days following the methods outlined in previous research[65] and Figure 2. All propagations were performed at room temperature on a platform orbital shaker (InnovaTM 2000, New Brunswick Scientific; Edison, NJ, USA) set to $150 \mathrm{rpm}$. Yeast cell counts and viability testing with methylene blue were performed on all propagations and fermentations according to standard methods [66].

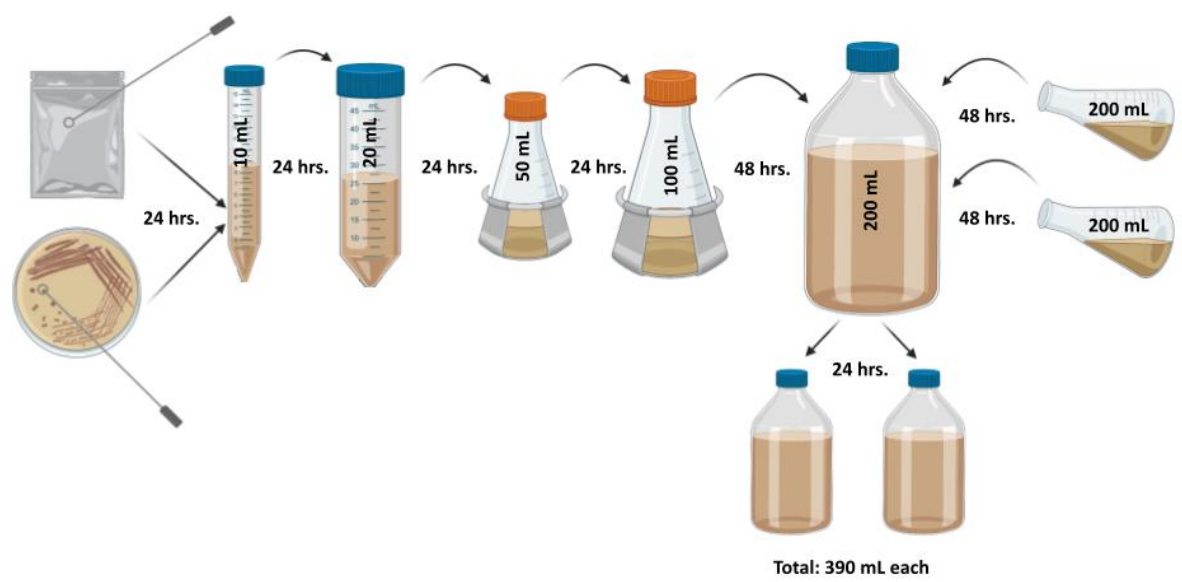

Figure 2. Yeast propagation schematic following previous methods[65]. Yeasts were propagated to a final approximate total of $40.0 \times 10^{10}$ cells in each bottle with a total of $390 \mathrm{~mL}$ of propagation wort, equivalent to the 
standard ale pitch rate of $1.0 \times 10^{6}$ cells per $\mathrm{mL}$ per ${ }^{\circ} \mathrm{P}$ [67] for each $40 \mathrm{~L}, 10^{\circ} \mathrm{P}$ pilot fermentation. Figure created on BioRender.com, not to scale.

\section{c. Pilot Scale Fermentations}

Pilot fermentations were performed in 56.0 L glycol-cooled cylindroconical fermenters (JV Northwest; Canby, OR, USA) filled to $40.0 \mathrm{~L}$ and set to a standard ale temperature of $20.0^{\circ} \mathrm{C}$. Each unique Saccharomyces species (Table 1) was pitched to its own fermenter in duplicate, with the control S. cerevisiae US-05 duplicates fermented in biological triplicate for quality assurance, totaling twenty distinct fermentations. One fermenter in each yeast pair received 10.0 g/L Centennial (8.3\% AA, Hopsteiner, New York, NY) T-90 hop pellets as a dry-hop when the measured gravity decreased to below $4.0^{\circ} \mathrm{P}$ or at seven days into fermentation, whichever occurred first. This amount of dry-hopping has become standard practice among craft breweries today, with many brewers far exceeding this amount at times $[29,30,68,69]$. End of fermentation or "terminal gravity" [70] was defined here as a change of less than $0.10^{\circ} \mathrm{P}$ gravity for two simultaneous days following dry-hop.

After fermentation was completed, all beer in all fermenters except the $S$. cerevisiae and $S$. pastorianus controls were cold conditioned at $0.0^{\circ} \mathrm{C}$ for two days to allow for natural clarification. Yeast and hops were removed from the bottom of the cylindroconical fermenter before the beer was transferred to a 19.6 L Sankey keg for carbonation. All were packaged from the kegs into $\mathrm{CO}_{2}$-purged $0.95 \mathrm{~L}$ (32 oz.) “Crowler” cans (Ball Corporation; Westminster, CO, USA) and stored below $4.0^{\circ} \mathrm{C}$ until sensory analysis and shipping. 


\section{d. Sample Collection and Preparation}

Fermenting beers were aseptically sampled daily within a two-hour window of the time of knockout transfer of wort to fermenter. $50 \mathrm{~mL}$ conical tubes of each sample were centrifuged (ThermoFisher Scientific; Waltham, MA, USA) at $20^{\circ} \mathrm{C}$ and $3000 \mathrm{x} \mathrm{g} \mathrm{RCF}$ for five minutes. The clarified supernatant was then degassed for five minutes using the degas setting on a VWR B1500A-DTH 1.90 L ultrasonic cleaner (Radnor, PA, USA). Degassed samples were then decanted into the sample tubes of the Anton Paar (Graz, Austria, EU) auto-sampling carousel for immediate analysis. Samples were then measured for extract, gravity, alcohol [71], real degrees of fermentation (RDF), and calories using an Anton Paar Density Meter (DMA 5000 M) and alcolyzer (Alcolyzer Beer M). The DMA $5000 \mathrm{M}$ has a repeatability within $0.000001 \mathrm{~g} / \mathrm{mL}$ and the Alcolyzer Beer $\mathrm{M}$ has a repeatability within $0.03{ }^{\circ} \mathrm{P}$ and $0.01 \% \mathrm{v} / \mathrm{v}$ alcohol. $\mathrm{pH}$ was measured on a ThermoFisher Scientific benchtop $\mathrm{pH}$ meter that received a weekly three-point calibration.

\section{e. Sensory Analysis}

Each set of packaged beer from an individual fermentation was assigned a randomly selected three-digit code in order to ensure blind analysis of experimental samples. The willing members of the UC Davis Brewing and Malting Science laboratory team $(n=7)$ used a modified consensus method [72] with check-all-that-apply (CATA) [73] in two tastings to choose appropriate aroma descriptors from the DraughtLab Beer Flavor Map ${ }^{\odot}$ (Fig. 3) for the twelve beers being analyzed. S. cerevisiae and S. pastorianus controls fermentations were not included. The lab members assessed beers served in $60 \mathrm{~mL}$ volumes in clear straight sided glasses, after being removed from cold storage $\left(4.0^{\circ} \mathrm{C}\right)$, under white light. Consensus panelists were instructed to cleanse their palates with water and unsalted crackers between each sample. 
The common aroma descriptors were parsed down to the twelve most recurrent amongst the experimental beers. Each of these twelve descriptors, the five accepted taste modalities, and three recurrent mouthfeel descriptors from the consensus panel were placed on a 9-point intensity scale for scoring by the local brewery panelists (Table 2).

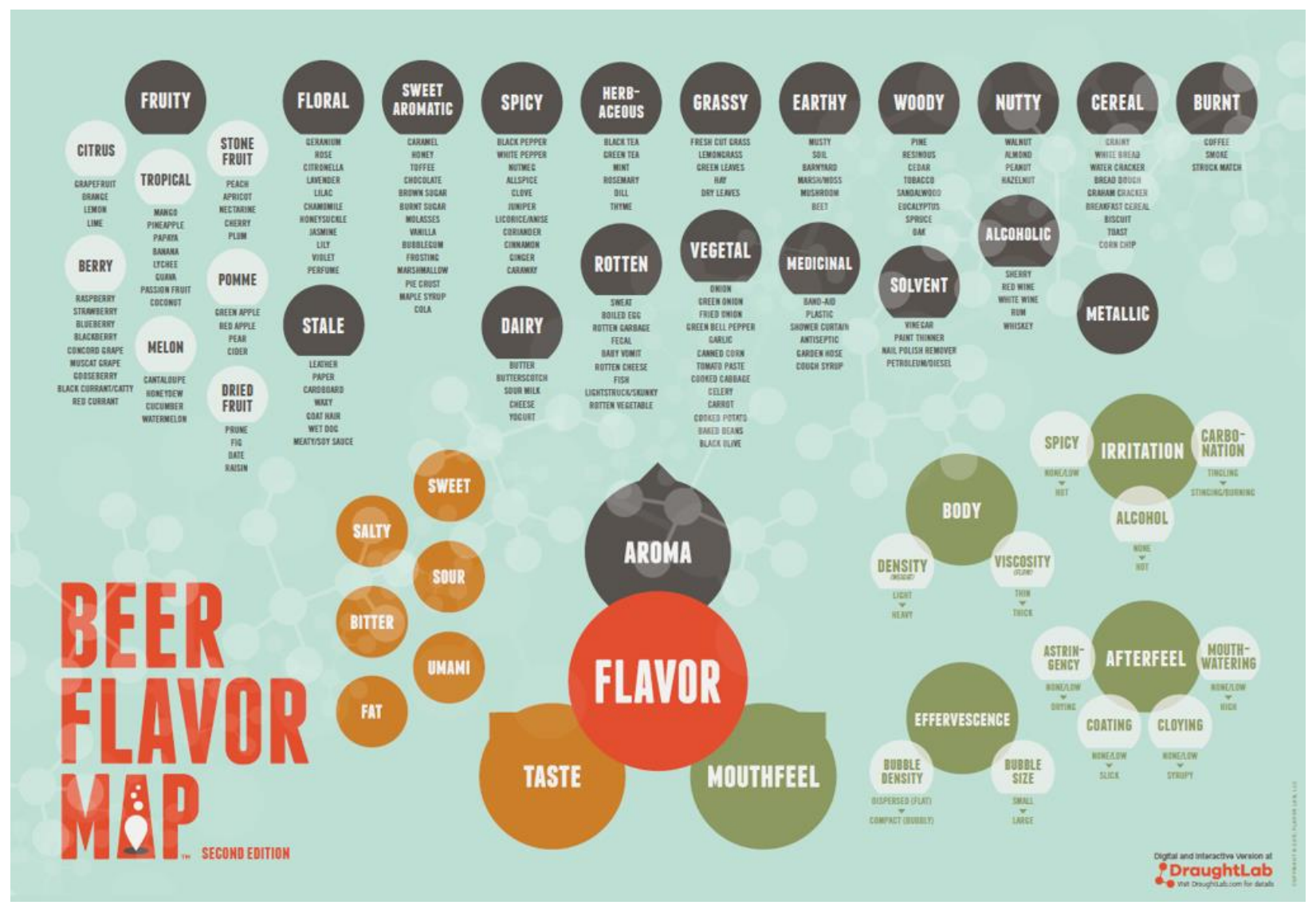

Figure 3. Beer Flavor Map@, as provided by DraughtLab, that outlines the flavor descriptors common to beer and was used to determine terms for consensus method and subsequent descriptive analysis.

Beers were cold transferred to local breweries within three weeks of packaging for sensory analysis with the descriptors previously determined via consensus. Trained beer sensory taste panels at Lagunitas Brewing Company (Petaluma, CA, USA), Deschutes Brewery (Bend, OR, USA), Russian River Brewing Company (Windsor, CA, USA), Sierra Nevada Brewing Company (Chico, CA, USA), Budweiser Brewery (Fairfield, CA, USA), and Sudwerk Brewing 
Company (Davis, CA, USA) used the descriptors determined previously by consensus method and rated each on a 9-point intensity scale from "none" to "extremely strong" [74,75]. Training, methods and frequency of sensory panels varied from brewery to brewery, however it was minimally required that the panelists were able to accurately distinguish dry-hopped from nonhopped beer and identify German, Belgian, and American ale strain characteristics. The total sample group to perform sensory analysis on the experimental beers consisted of 51 panelists (36 male and 15 female), ranging in age from 24 to 61 . No panelists had medical reasons for not consuming alcohol. 
Table 2. Sample ballot given to brewery taste panels accompanying the beer for sensory analysis. Aroma attributes determined from consensus method with CATA performed by UC Davis Brewing Lab members.

\begin{tabular}{|c|c|c|c|c|c|c|c|c|c|c|}
\hline Beer: $\mathbf{X X X}$ & & & & Sex: & M & / & $\mathrm{F}$ & & Age: & \\
\hline \multicolumn{11}{|c|}{ Score each attribute by circling a number, with $0=$ none to $9=$ extremely strong } \\
\hline \multicolumn{11}{|c|}{ Aroma: } \\
\hline Cereal: Grainy, Biscuit, Cracker, Wort & 0 & 1 & 2 & 3 & 4 & 5 & 6 & 7 & 8 & 9 \\
\hline Earthy: Musty, Barnyard, Mushroom & 0 & 1 & 2 & 3 & 4 & 5 & 6 & 7 & 8 & 9 \\
\hline Spicy: Clove, Black Pepper, Ginger & 0 & 1 & 2 & 3 & 4 & 5 & 6 & 7 & 8 & 9 \\
\hline Grassy: Fresh Cut, Dry Leaves, Green, Hay & 0 & 1 & 2 & 3 & 4 & 5 & 6 & 7 & 8 & 9 \\
\hline Citrus: Grapefruit, Orange, Lemon, Lime & 0 & 1 & 2 & 3 & 4 & 5 & 6 & 7 & 8 & 9 \\
\hline Tropical: Mango, Papaya, Guava, Banana & 0 & 1 & 2 & 3 & 4 & 5 & 6 & 7 & 8 & 9 \\
\hline Stone Fruit: Apricot, Nectarine, Peach & 0 & 1 & 2 & 3 & 4 & 5 & 6 & 7 & 8 & 9 \\
\hline Stale: Cardboard, Goat Hair, Oxidation, Meaty & 0 & 1 & 2 & 3 & 4 & 5 & 6 & 7 & 8 & 9 \\
\hline Vegetal: Cooked Vegetable, Onion, Celery & 0 & 1 & 2 & 3 & 4 & 5 & 6 & 7 & 8 & 9 \\
\hline Solvent: Chemical, Paint Thinner, Nail Polish Remover & 0 & 1 & 2 & 3 & 4 & 5 & 6 & 7 & 8 & 9 \\
\hline Rotten: Baby Vomit, Sweat, Boiled Egg & 0 & 1 & 2 & 3 & 4 & 5 & 6 & 7 & 8 & 9 \\
\hline Metallic & 0 & 1 & 2 & 3 & 4 & 5 & 6 & 7 & 8 & 9 \\
\hline Other: (Write In) & 0 & 1 & 2 & 3 & 4 & 5 & 6 & 7 & 8 & 9 \\
\hline \multicolumn{11}{|c|}{ Taste: } \\
\hline Sweet & 0 & 1 & 2 & 3 & 4 & 5 & 6 & 7 & 8 & 9 \\
\hline Bitter & 0 & 1 & 2 & 3 & 4 & 5 & 6 & 7 & 8 & 9 \\
\hline Sour & 0 & 1 & 2 & 3 & 4 & 5 & 6 & 7 & 8 & 9 \\
\hline Salty & 0 & 1 & 2 & 3 & 4 & 5 & 6 & 7 & 8 & 9 \\
\hline Umami & 0 & 1 & 2 & 3 & 4 & 5 & 6 & 7 & 8 & 9 \\
\hline \multicolumn{11}{|c|}{ Mouthfeel: } \\
\hline Body & 0 & 1 & 2 & 3 & 4 & 5 & 6 & 7 & 8 & 9 \\
\hline Alcohol & 0 & 1 & 2 & 3 & 4 & 5 & 6 & 7 & 8 & 9 \\
\hline Astringency & 0 & 1 & 2 & 3 & 4 & 5 & 6 & 7 & 8 & 9 \\
\hline
\end{tabular}




\section{f. Statistical Analysis}

Standard deviation values, two-tailed statistical analysis ( $t$-test) of fermentation data with corresponding $p$-values, as well as two-way analysis of variance (ANOVA) and coefficients of variance for sensory data were performed in Microsoft® Excel 2019, Version 2102 (Build 13801.20360).

\section{Results and Discussion}

\section{a. Pilot Fermentations}

Ten total brews were performed for the twenty fermentations, with a mean original gravity (O.G.) of $10.2^{\circ}$ Plato $( \pm 0.36)$, and a higher brewhouse efficiency than expected for the recipe designed at $10.0^{\circ} \mathrm{P}$ (Fig. 4). Fermentations were carried out at $20.0^{\circ} \mathrm{C}$, standard ale temperatures, and analytical parameters were measured on each day of fermentation. Results were compared with the two control strains, S. cerevisiae US-05 and S. pastorianus W 34/70. Vigorous fermentations of the control species suggest an adequate yeast pitching rate, nutrients levels, and wort aeration were utilized. All fermentations reached terminal gravity within two weeks, with the exception of S. uvarum UCDFST 11-512, which took fifteen days for the non-hopped fermentation but only eleven days for the dry-hopped fermentation (Table 3). However, all average fermentation lengths were not shown to be statistically different between dry-hopped and non-hopped fermentations $(p>0.05)$. These fermentation lengths indicate all the yeasts studied here are viable candidates for production breweries that normally ferment lagers, but perhaps too long for breweries that normally produce ales. Conditioning time was not accounted for in this study, as all fermentations were deemed terminal based on gravity instead of from the presence of secondary metabolites, such as diacetyl or acetaldehyde concentrations. 


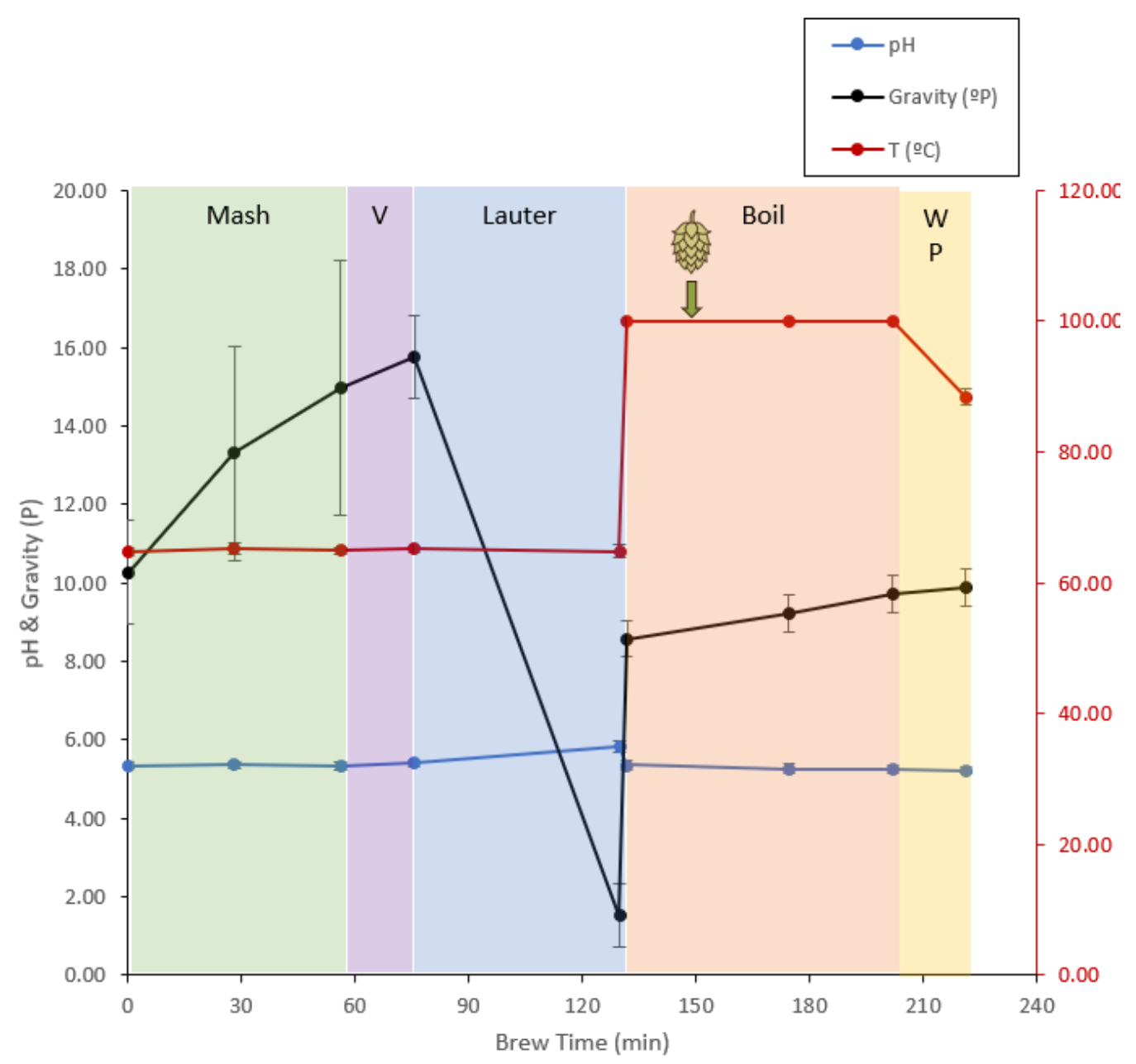

Figure 4. Average of standard brew day analytical parameters, with error bars representing standard deviation. 
Table 3. Terminal fermentation characteristics of Saccharomyces species and reference strains used to ferment all-malt wort at $40.0 \mathrm{~L}$ pilot scale under two different conditions: non-hopped or dry-hopped during fermentation. Measurements of original gravity (O.G.), final gravity (F.G.), alcohol by volume (ABV), real degree of fermentation (RDF), and calories (Cal) performed on Anton Paar Alcolyzer Beer M. Viability was performed from cells in suspension on nonhopped beers on day of terminal gravity, stained with methylene blue, as per standard procedure (69). Viability was not performed on dry-hopped beers due to interference from hops in suspension. Fermentation length as given in days to achieve final gravity. Strain listed as "Hybrid" is interspecies hybrid of $S$. bayanus x S. cerevisiae from LeSaffre R\&D.

\begin{tabular}{|c|c|c|c|c|c|c|c|c|}
\hline & $\begin{array}{c}\text { S. kudriavzevii } \\
11-515 \\
\end{array}$ & $\begin{array}{c}\text { S. paradoxus } \\
01-161 \\
\end{array}$ & $\begin{array}{c}\text { S. mikatae } \\
11-510 \\
\end{array}$ & $\begin{array}{c}\text { S. bayanus } \\
01-135 \\
\end{array}$ & $\begin{array}{c}\text { S. uvarum } \\
11-512 \\
\end{array}$ & $\begin{array}{l}\text { Hybrid } \\
\text { HD T18 } \\
\end{array}$ & $\begin{array}{c}\text { S. cerevisiae } \\
\text { US-05* }\end{array}$ & $\begin{array}{c}\text { S. pastorianus } \\
\text { W } 34 / 70 \\
\end{array}$ \\
\hline \multicolumn{9}{|c|}{ Non-Hopped } \\
\hline O.G. $\left({ }^{\circ} \mathrm{P}\right)$ & 10.0 & 10.1 & 10.1 & 10.3 & 10.4 & 9.80 & $10.3 \pm 0.6$ & 10.4 \\
\hline F.G. $\left({ }^{\circ} P\right)$ & 1.93 & 3.43 & 8.75 & 2.10 & 3.33 & 3.32 & $1.99 \pm 0.36$ & 1.84 \\
\hline$A B V(\% v / v)$ & 4.26 & 3.78 & 0.95 & 4.51 & 3.74 & 3.56 & $4.44 \pm 0.19$ & 4.45 \\
\hline RDF (\%) & 66.4 & 55.9 & 14.2 & 66.1 & 56.2 & 55.4 & $66.6 \pm 1.63$ & 67.5 \\
\hline Cal (kJ/100 mL) & 150 & 160 & 163 & 160 & 157 & 152 & $156 \pm 10.6$ & 154 \\
\hline $\mathrm{pH}$ & 4.24 & 4.45 & 4.60 & 4.31 & 4.48 & 4.16 & $4.36 \pm 0.06$ & 4.42 \\
\hline Viability (\%) & $80.7 \pm 2.4$ & $97.1 \pm 0.8$ & $99.0 \pm 0.5$ & $83.7 \pm 1.9$ & $81.6 \pm 4.5$ & $* *$ & $* *$ & $* *$ \\
\hline Ferm. Length (days) & 13 & 10 & 8 & 6 & 15 & 9 & $8.33 \pm 0.58$ & 6 \\
\hline \multicolumn{9}{|c|}{ Dry-Hopped } \\
\hline Original Gravity $\left({ }^{\circ} \mathrm{P}\right)$ & 10.0 & 10.1 & 10.1 & 10.3 & 10.4 & 9.80 & $10.3 \pm 0.6$ & 10.4 \\
\hline Final Gravity ( $\left.{ }^{\circ} \mathrm{P}\right)$ & 1.79 & 3.44 & 8.96 & 1.64 & 3.39 & 3.09 & $1.69 \pm 0.42$ & 1.57 \\
\hline Alcohol (\% v/v) & 4.43 & 3.91 & 0.92 & 4.85 & 3.86 & 3.91 & $4.69 \pm 0.20$ & 4.76 \\
\hline $\operatorname{RDF}(\%)$ & 67.8 & 56.5 & 13.5 & 69.8 & 56.5 & 58.2 & $69.2 \pm 2.19$ & 70.0 \\
\hline Calories $(\mathrm{kJ} / 100 \mathrm{~mL})$ & 153 & 163 & 165 & 162 & 161 & 158 & $159 \pm 11.5$ & 159 \\
\hline $\mathrm{pH}$ & 4.47 & 4.68 & 4.75 & 4.47 & 4.55 & 4.45 & $4.64 \pm 0.02$ & 4.70 \\
\hline Ferm. Length (days) & 13 & 11 & 9 & 8 & 11 & 10 & $10.0 \pm 1.0$ & 8 \\
\hline
\end{tabular}

* indicates the mean of the three biological replicates **data not recorded 
All yeasts measured for viability showed greater than $80.0 \%$ living cells at the end of fermentation, signifying a potential for serial re-pitching in a commercial setting. Viability was not measured on the two control strains, US-05 and W 34/70, as their ability for propagation and serial re-pitching has been extensively studied [76-78]. Viability data for S. bayanus x $S$. cerevisiae HD T18 was not available and should be further evaluated as it is not standard practice to re-pitch wine yeasts due to ethanol toxicity [79].

When comparing the dry-hopped and non-hopped fermentations, average differences for alcohol, calorie, and $\mathrm{pH}$ measurements between the two treatments when comparing each yeast species were highly significant $(p<0.01)$, and less so when measuring RDF $(p<0.05)$. Dryhopping has been shown to biochemically change the composition of wort during fermentation, allowing yeast access to a greater amount of fermentable sugars and subsequent additional fermentative capacity, a phenomenon known as hop creep [80-84]. Most of the novel yeasts shown here show no ability to mitigate the hop creep phenomenon in an effective manner, as all yeasts, with the exception of S. mikatae UCDFST 11-510, showed increases in RDF (Table 3) and alcohol (Fig. 5) from the addition of dry-hops during fermentation. 

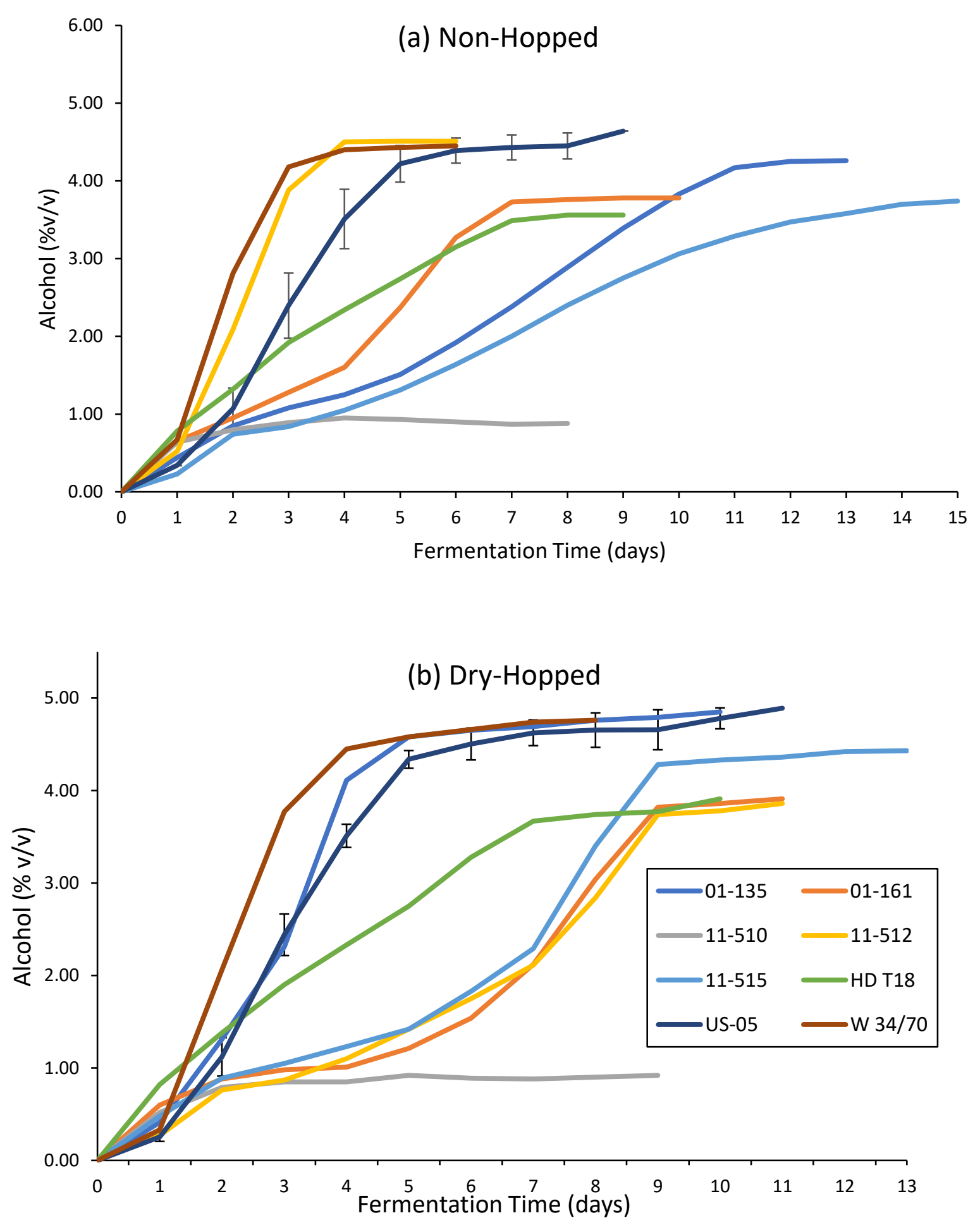

Figure 5. Alcohol content by volume measured daily on the Anton Paar Alcolyzer Beer M, as reported for both (a) non-hopped and (b) dry-hopped fermentations of all yeasts in this study. Results for US-05 are reported as the mean of three biological replicates with error bars for standard deviation at each day of fermentation. 
Fermentation kinetics were grouped more closely in the dry-hopped fermentations compared to the non-hopped treatment (Fig. 5), with S. bayanus UCDFST 01-135 showing the most similar fermentation profile to both of the control strains, and S. kudriavzevii UCDFST 11515, S. paradoxus UCDFST 01-161, and S. uvarum UCDFST 11-512 showing slower, yet steady fermentation. S. paradoxus UCDFST 01-161 showed decreased kinetics with the addition of dryhops (Fig. 5b), but was still a slower fermenter than the control strains in both treatments. The $S$. cerevisiae x S. bayanus hybrid HD T18 showed no change in kinetics with the addition of dryhops, showing moderate and steady fermentative capacity, with a terminal RDF similar to $S$. paradoxus UCDFST 01-161 and S. uvarum UCDFST 11-512. The $S$. cerevisiae x S. bayanus hybrid HD T18 fermented to a lower relative alcohol content than these other strains due to it starting from a brew with the lowest O.G.

Of note, is the strain UCDFST 11-510, S. mikatae, as it was an outlier from the group with the lowest RDF (Table 3) and final amount of alcohol produced, whether dry-hopped or not (Fig. 5). UCDFST $11-510$ recorded $99.0 \pm 0.5 \%$ yeast viability in suspension at the end of fermentation, yet only $14.2 \%$ RDF in the non-hopped treatment. This indicates the strain is a potential candidate for low or no alcohol beer fermentations if brewing parameters are adjusted to get the final alcohol below $0.5 \%(\mathrm{v} / \mathrm{v})$ and considerations are taken for microbial stability. Analysis of the sugars remaining in this beer may aid in determining which carbohydrates this $S$. mikatae strain was able to assimilate during fermentation. Additionally, this species has been shown to form a pellicle on top of fermenting beer after twenty-five days at $20{ }^{\circ} \mathrm{C}$ [43], suggesting it may ferment comparably slowly as wild-type yeasts, such as Brettanomyces or Hanseniaspora spp. Further research regarding S. mikatae in fermentation for the production of low and no alcohol beers should be performed. 


\section{b. Sensory Analysis}

The flavor of the beers from these fermentations was investigated for aroma, taste, and mouthfeel in order to further qualify the brewing potential of these novel Saccharomyces yeasts. Modified consensus method from the UC Davis Brewing and Malting Science lab members yielded twelve aroma and three mouthfeel descriptors that were deemed most discriminant and non-redundant from the Beer Flavor Map@ as provided by DraughtLab. The most commonly agreed upon descriptors included Cereal, Earthy, Spicy, Grassy, Citrus, Tropical, Stone Fruit, Stale, Vegetal, Solvent, Rotten, and Metallic for aroma, with additional descriptors within each aroma category outlined above (Table 2). DraughtLab software was used to confirm that statistically significant differences were observed for all of the consensus CATA terms after accounting for both panelist and replication effects. Body, Alcohol, and Astringency were selected as the most common mouthfeel descriptors.

From the panelists at participating breweries, all beers showed increases in bitterness and astringency from the high level of dry-hopping (Fig 6), suggesting beer clarification prior to packaging may have been necessary to fully distinguish the effects of the hops without particulates in suspension effecting flavor. The base beer was also of low alcohol and IBU content, which could contribute to perceived bitterness from the increase of humulinones from dry-hopping a low IBU beer [85], or perceived astringency from the increase of polyphenol content [80]. Dry-hopping increased the fruit (Citrus, Tropical, and Stone Fruit) perception on all beers as expected from the Centennial cultivar used here [86], with the exception of Stone Fruit in UCDFST 01-161 S. paradoxus.

All experimental beers displayed Spicy aromas, likely from the expression of phenols, but genetic testing for the POF phenotype should be performed to confirm [87]. Interestingly, these 
Spicy aromas were perceived lower in the dry-hopped beers, in contrast to expectations, as resinous and spicy characteristics are also noted as aroma characteristics of Centennial hops. On average, many of the unique attributes perceived in the beers fermented with these yeasts can be generally considered as off-flavors in beer (Solvent, Metallic, Vegetal, Rotten, or Stale). Trained panelists perceived these descriptors in very low amounts, with no off-flavor characteristic achieving an average greater than 2 on the 9-point intensity scale. 


\section{S. cerevisiae $\times$ S. bayanus HD T18}

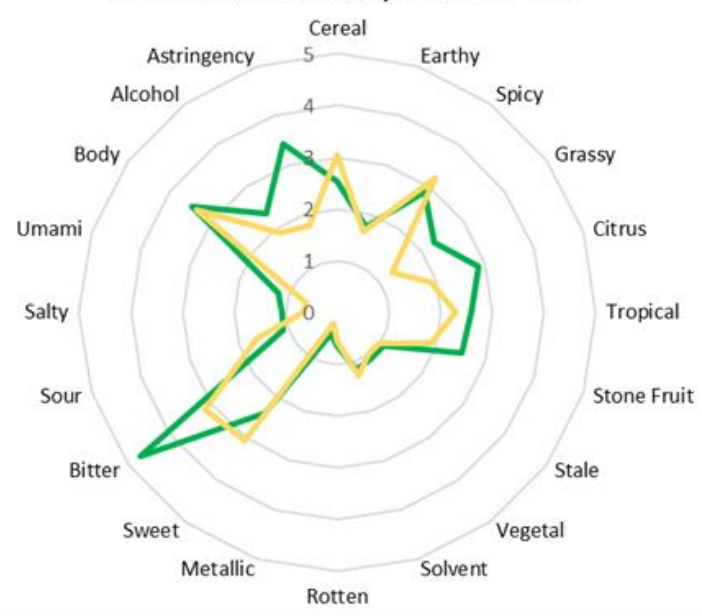

S. uvarum UCDFST $11-512$

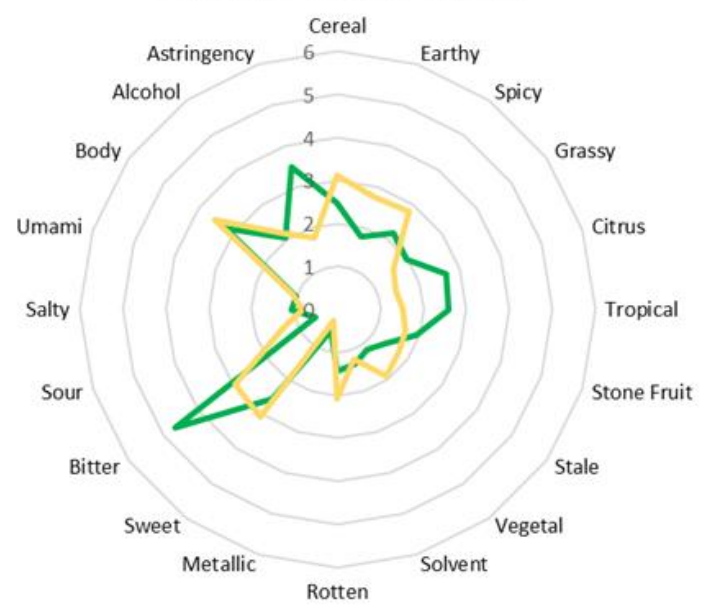

\section{S. bayanus UCDFST 01-135}

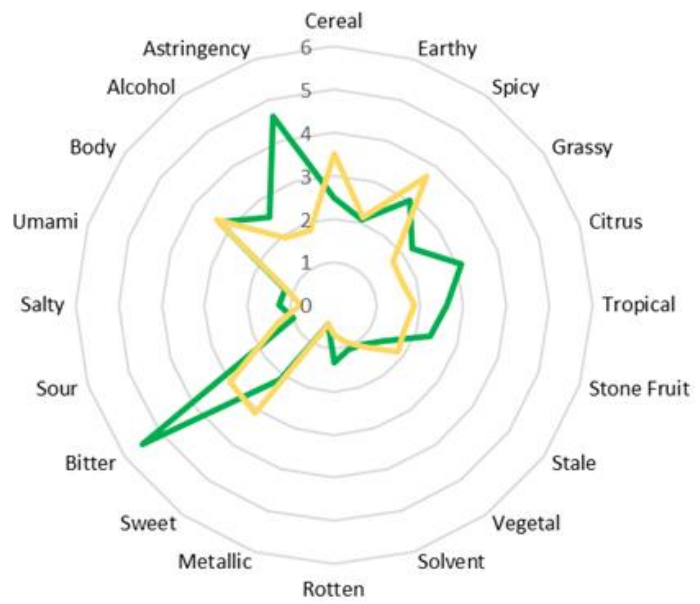

S. kudriavzevii UCDFST 11-515

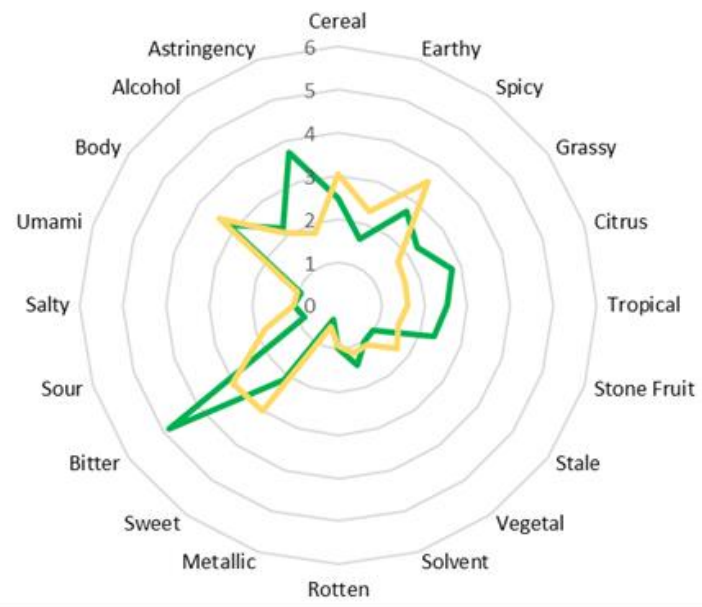

\section{S. mikatae UCDFST $11-510$}

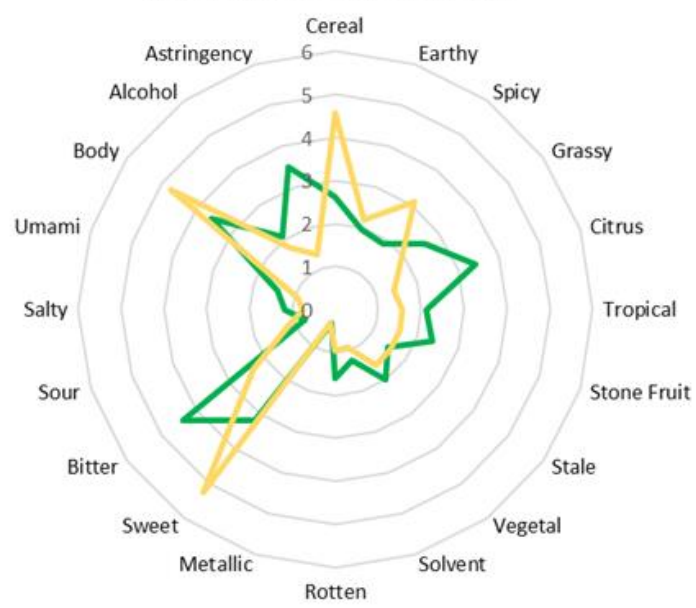

S. paradoxus UCDFST 01-161

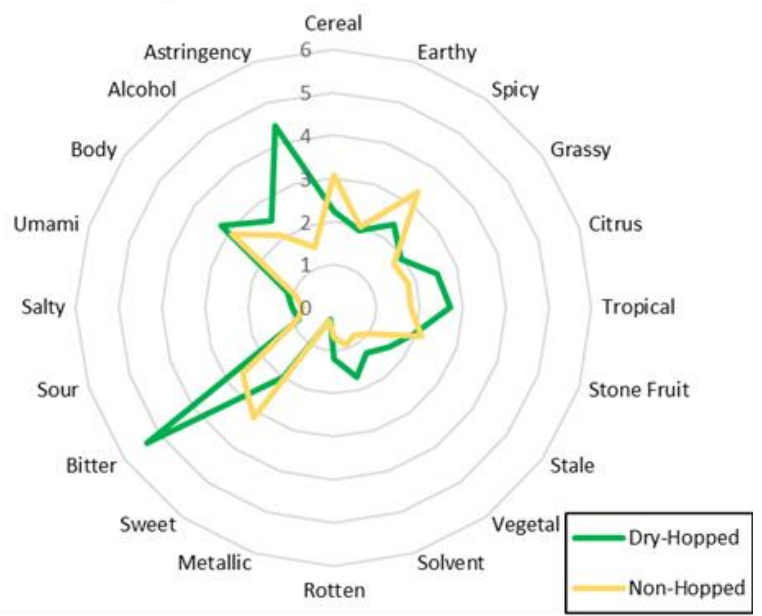

Figure 6. Radar charts of attributes for each experimental yeast fermentation in this study. Dry-hopped treatments are shown in green, while non-hopped are shown in yellow. ( $\mathrm{n}=51$, with 36 male and 15 female) 
Other descriptors were written in on the ballot (Table 2) by the trained panelists at breweries. Beers made with S. uvarum UCDFST 11-512 commonly had notes of diacetyl in the dry-hopped treatment and sulfur in the non-hopped fermentation. Beers made with $S$. kudriavzevii UCDFST 11-515 were described as having distinct phenolic and sulfur characteristics in the non-hopped treatment. The non-hopped beer fermented with S. mikatae UCDFST 11-510 was perceived as being wort-like, likely due to its low attenuation. Descriptors are given only if more than $10 \%$ of panelists $(n=5)$ reported a given characteristic.

\section{Conclusion}

Fermentation kinetics and yeast viabilities here suggest appropriate pitching rate, adequate nutrients, and proper aeration from the brewhouse were achieved on all brews and fermentations. All yeasts reached terminal gravity in under two weeks, with the exception of $S$. uvarum UCDFST 11-512, which took fifteen days for the non-hopped fermentation. These kinetics makes all the yeasts studied viable candidates for production breweries, but conditioning time should be accounted for but were not studied here. All fermentations in this study were deemed terminal based on gravity as opposed to metabolite production, so further analysis and brewer-specific standards are required. All yeasts displayed high potential for re-pitching in a commercial setting with high viabilities at the end of fermentation in the non-hopped fermentations. These high numbers are promising, but viability should be assessed during fermentation and prior to re-pitch in order to ensure adequate cell count for vigorous growth in a commercial setting.

With the exception of S. mikatae UCDFST 11-510, all yeasts displayed increased RDF and alcohol with the addition of dry-hops during fermentation, as was expected due to hop creep. Further research should be pursued in the use of $S$. mikatae UCDFST 11-510 and other strains of 
this species for the production of low and no alcohol beers and its possible resistance to hop creep. Strong phenolic characteristics were perceived in the flavor of beers fermented with all yeasts, but dry-hopping, in this case with Centennial, decreased this aroma while increasing all fruit aromas, as well as bitterness and astringency. No flavors that are generally associated with poor fermentation scored high among trained sensory panels. Comparisons to standard beer yeast fermentations should have been performed in sensory analysis as well, but experimental design mistakes and time constraints did not allow. Previous research has shown these yeasts' ability to co-ferment with standard S. cerevisiae, and flavor analysis should also be performed on these potential combinations. All of these species in the Sss displayed great brewing potential given a brewery's desire to experiment with flavor and willingness to bring in a new yeast.

\section{Acknowledgements}

Much gratitude to Anne Flesch and Kevin Lane of Fermentis, as well as Professor Kyria Boundy-Mills and Dr Irnayuli Sitepu from the UC Davis Phaff Collection for advice in yeast selection and revival of cryogenically stored yeast. Appreciation to Lindsey Barr and Victoria Chaplin at DraughtLab for providing access to their amazing sensory software. Thanks to Professor Jean-Xavier Guinard and Lindsey Barr for helping formulate the way to run this sensory analysis during a global COVID pandemic. Many thanks to Joy Wilson of Lagunitas Brewing, Amanda Benson of Deschutes Brewery, Vinnie Cilurzo of Russian River Brewing, Katrina Kettler of Budweiser Fairfield, Andrew Reyes of Sierra Nevada Brewing, and Alex Patil of Sudwerk Brewing for helping coordinate sensory panels for these beers. Thanks to the UC Davis Food Science and Technology Department for their financial support, as well as funds from the H.A. Jastro-Shields Research Award, Margrit Mondavi Graduate Fellowship, and Michael J. Lewis Endowment. 


\section{Conflicts of Interests}

The authors declare no conflicts of interest.

\section{Author contributions}

J.B. conceived the study, performed the bulk of the research, gathered and transcribed data, and wrote the original manuscript. A.M. assisted in the brewing of beer and brew day sample collection, data curation with figure manipulation and statistics, and assisted with the final editing of the manuscript. G.F. supervised the work, offered insight, and assisted with final editing of the manuscript. All authors have read and agreed to the published version of the manuscript.

\section{References}

1. Humia, B. V.; Santos, K. S.; Barbosa, A. M.; Sawata, M.; Mendonça, M. da C.; Padilha, F. F. Beer molecules and its sensory and biological properties: A review. Molecules 2019, 24, doi:10.3390/molecules24081568.

2. Tian, J. Determination of several flavours in beer with headspace sampling-gas chromatography. Food Chem. 2010, 123, 1318-1321, doi:10.1016/j.foodchem.2010.06.013.

3. Aquilani, B.; Laureti, T.; Poponi, S.; Secondi, L. Beer choice and consumption determinants when craft beers are tasted: An exploratory study of consumer preferences. Food Qual Prefer 2015, 41, 214-224, doi:10.1016/j.foodqual.2014.12.005.

4. Dykstra, J. The Beer Connoisseur. Café Media, Atlanta, GA, USA, January 7, 2020; pp. 18-29.

5. Bellut, K.; Michel, M.; Zarnkow, M.; Hutzler, M.; Jacob, F.; De Schutter, D.; Daenen, L.; Lynch, K.; Zannini, E.; Arendt, E. Application of Non-Saccharomyces Yeasts Isolated from Kombucha in the Production of Alcohol-Free Beer. Fermentation 2018, 4, 66, doi:10.3390/fermentation4030066.

6. Bellut, K.; Arendt, E. K. Chance and Challenge: Non-Saccharomyces Yeasts in Nonalcoholic and Low Alcohol Beer Brewing - A Review. ASBCJ 2019, 77, 1-15, doi:10.1080/03610470.2019.1569452.

7. Gibson, B.; Geertman, J. M. A.; Hittinger, C. T.; Krogerus, K.; Libkind, D.; Louis, E. J.; Magalhães, F.; Sampaio, J. P. New yeasts-new brews: modern approaches to brewing yeast design and development. FEMS Yeast Res 2017, 17, doi:10.1093/femsyr/fox038. 
8. Krogerus, K.; Magalhães, F.; Vidgren, V.; Gibson, B. Novel brewing yeast hybrids: creation and application. Appl. Microbiol. Biotechnol. 2017, 101, 65-78, doi:10.1007/s00253-016-8007-5.

9. Basso, R. F.; Alcarde, A. R.; Portugal, C. B. Could non-Saccharomyces yeasts contribute on innovative brewing fermentations? Food Res. Int 2016, 86, 112-120, doi:10.1016/j.foodres.2016.06.002.

10. Varela, C. The impact of non-Saccharomyces yeasts in the production of alcoholic beverages. Appl. Microbiol. Biotechnol. 2016, 100, 9861-9874, doi:10.1007/s00253-0167941-6.

11. Canonico, L.; Agarbati, A.; Comitini, F.; Ciani, M. Torulaspora delbrueckii in the brewing process: A new approach to enhance bioflavour and to reduce ethanol content. Food Microbiol 2016, 56, 45-51, doi:10.1016/j.fm.2015.12.005.

12. Gamero, A.; Dijkstra, A.; Smit, B.; de Jong, C. Aromatic Potential of Diverse NonConventional Yeast Species for Winemaking and Brewing. Fermentation 2020, 6, 50, doi:10.3390/fermentation6020050.

13. Capece, A.; Romaniello, R.; Pietrafesa, A.; Siesto, G.; Pietrafesa, R.; Zambuto, M.; Romano, P. Use of Saccharomyces cerevisiae var. boulardii in co-fermentations with $S$. cerevisiae for the production of craft beers with potential healthy value-added. Int. J. Food Microbiol. 2018, 284, 22-30, doi:10.1016/j.ijfoodmicro.2018.06.028.

14. Tyakht, A.; Kopeliovich, A.; Klimenko, N.; Efimova, D.; Dovidchenko, N.; Odintsova, V.; Kleimenov, M.; Toshchakov, S.; Popova, A.; Khomyakova, M.; Merkel, A. Characteristics of bacterial and yeast microbiomes in spontaneous and mixed-fermentation beer and cider. Food Microbiol 2021, 94, 103658, doi:10.1016/j.fm.2020.103658.

15. Marongiu, A.; Zara, G.; Legras, J.-L.; Del Caro, A.; Mascia, I.; Fadda, C.; Budroni, M. Novel starters for old processes: use of Saccharomyces cerevisiae strains isolated from artisanal sourdough for craft beer production at a brewery scale. J. Ind. Microbiol. Biotechnol. 2015, 42, 85-92, doi:10.1007/s10295-014-1525-1.

16. Peris, D.; Lopes, C. A.; Belloch, C.; Querol, A.; Barrio, E. Comparative genomics among Saccharomyces cerevisiae $\times$ Saccharomyces kudriavzevii natural hybrid strains isolated from wine and beer reveals different origins. BMC Genomics 2012, 13, 407, doi:10.1186/1471-2164-13-407.

17. Krogerus, K.; Preiss, R.; Gibson, B. A Unique Saccharomyces cerevisiae $\times$ Saccharomyces uvarum Hybrid Isolated From Norwegian Farmhouse Beer: Characterization and Reconstruction. Front. Microbiol. 2018, 9, 2253, doi:10.3389/fmicb.2018.02253.

18. Mulero-Cerezo, J.; Briz-Redón, Á.; Serrano-Aroca, Á. Saccharomyces cerevisiae var. boulardii: valuable probiotic starter for craft beer production. Appl. Sci. 2019, 9, 3250, doi:10.3390/app9163250. 
19. Peris, D.; Pérez-Torrado, R.; Hittinger, C. T.; Barrio, E.; Querol, A. On the origins and industrial applications of Saccharomyces cerevisiae $\times$ Saccharomyces kudriavzevii hybrids. Yeast 2018, 35, 51-69, doi:10.1002/yea.3283.

20. Kodama, Y.; Kielland-Brandt, M. C.; Hansen, J. Lager brewing yeast. In Comparative Genomics; Sunnerhagen, P., Piskur, J., Eds.; Springer Berlin Heidelberg: Berlin, Heidelberg, 2006; pp. 145-164.

21. Rainieri, S.; Kodama, Y.; Kaneko, Y.; Mikata, K.; Nakao, Y.; Ashikari, T. Pure and mixed genetic lines of Saccharomyces bayanus and Saccharomyces pastorianus and their contribution to the lager brewing strain genome. Appl. Environ. Microbiol. 2006, 72, 39683974, doi:10.1128/AEM.02769-05.

22. Nikulin, J.; Vidgren, V.; Krogerus, K.; Magalhães, F.; Valkeemäki, S.; Kangas-Heiska, T.; Gibson, B. Brewing potential of the wild yeast species Saccharomyces paradoxus. Eur. Food Res. Technol. 2020, doi:10.1007/s00217-020-03572-2.

23. Gibson, B.; Liti, G. Saccharomyces pastorianus: genomic insights inspiring innovation for industry. Yeast 2015, 32, 17-27, doi:10.1002/yea.3033.

24. Nakao, Y.; Kanamori, T.; Itoh, T.; Kodama, Y.; Rainieri, S.; Nakamura, N.; Shimonaga, T.; Hattori, M.; Ashikari, T. Genome sequence of the lager brewing yeast, an interspecies hybrid. DNA Res 2009, 16, 115-129, doi:10.1093/dnares/dsp003.

25. Bing, J.; Han, P.-J.; Liu, W.-Q.; Wang, Q.-M.; Bai, F.-Y. Evidence for a Far East Asian origin of lager beer yeast. Curr. Biol. 2014, 24, R380-1, doi:10.1016/j.cub.2014.04.031.

26. Wendland, J. Lager yeast comes of age. Eukaryotic Cell 2014, 13, 1256-1265, doi:10.1128/EC.00134-14.

27. Brown, H.; Morris, G. On Certain Functions of Hops Used in the Dry-Hopping of Beers. Trans. Inst. Brew 1893, 6, 94-106.

28. Moritz, E. R.; Morris, G. H. A Text-book of the Science of Brewing; Spon: London, UK, 1891.

29. LaFontaine, S. R.; Shellhammer, T. H. How hoppy beer production has redefined hop quality and a discussion of agricultural and processing strategies to promote it. $M B A A T Q$ 2019, doi:10.1094/TQ-56-1-0221-01.

30. Lafontaine, S. R.; Shellhammer, T. H. Investigating the Factors Impacting Aroma, Flavor, and Stability in Dry-Hopped Beers. MBAA TQ 2019, 56, 13-23, doi:10.1094/TQ-56-10225-01.

31. Mortimer, R. K. Evolution and variation of the yeast (Saccharomyces) genome. Genome Res. 2000, 10, 403-409, doi:10.1101/gr.10.4.403.

32. Sicard, D.; Legras, J.-L. Bread, beer and wine: yeast domestication in the Saccharomyces sensu stricto complex. C R Biol 2011, 334, 229-236, doi:10.1016/j.crvi.2010.12.016. 
33. Borneman, A. R.; Pretorius, I. S. Genomic insights into the Saccharomyces sensu stricto complex. Genetics 2015, 199, 281-291, doi:10.1534/genetics.114.173633.

34. Libkind, D.; Hittinger, C. T.; Valério, E.; Gonçalves, C.; Dover, J.; Johnston, M.; Gonçalves, P.; Sampaio, J. P. Microbe domestication and the identification of the wild genetic stock of lager-brewing yeast. Proc. Natl. Acad. Sci. USA 2011, 108, 14539-14544, doi:10.1073/pnas.1105430108.

35. Rodríguez, M. E.; Pérez-Través, L.; Sangorrín, M. P.; Barrio, E.; Querol, A.; Lopes, C. A. Saccharomyces uvarum is responsible for the traditional fermentation of apple chicha in Patagonia. FEMS Yeast Res 2017, 17, doi:10.1093/femsyr/fow109.

36. Demuyter, C.; Lollier, M.; Legras, J. L.; Le Jeune, C. Predominance of Saccharomyces uvarum during spontaneous alcoholic fermentation, for three consecutive years, in an Alsatian winery. J. Appl. Microbiol. 2004, 97, 1140-1148, doi:10.1111/j.13652672.2004.02394.x.

37. Cordente, A. G.; Curtin, C. D.; Varela, C.; Pretorius, I. S. Flavour-active wine yeasts. Appl. Microbiol. Biotechnol. 2012, 96, 601-618, doi:10.1007/s00253-012-4370-z.

38. Naumova, E.; Korshunova, I.; Jespersen, L.; Naumov, G. Molecular genetic identification of sensu stricto strains from African sorghum beer. FEMS Yeast Res 2003, 3, 177-184, doi:10.1016/S1567-1356(02)00191-5.

39. Mateo, J. J.; Jimenez, M.; Huerta, T.; Pastor, A. Contribution of different yeasts isolated from musts of monastrell grapes to the aroma of wine. Int. J. Food Microbiol. 1991, 14, 153-160, doi:10.1016/0168-1605(91)90102-U.

40. Bisson, L. F. Yeast hybrids in winemaking. Catalyst: Discovery into Practice 2017, 1, 2734, doi:10.5344/catalyst.2016.16001.

41. Bruner, J.; Fox, G. Novel Non-cerevisiae Saccharomyces Yeast Species Used in Beer and Alcoholic Beverage Fermentations. Fermentation 2020, 6, 116, doi:10.3390/fermentation6040116.

42. Nguyen, H.-V.; Legras, J.-L.; Neuvéglise, C.; Gaillardin, C. Deciphering the hybridisation history leading to the Lager lineage based on the mosaic genomes of Saccharomyces bayanus strains NBRC1948 and CBS380. PLoS One 2011, 6, e25821, doi:10.1371/journal.pone.0025821.

43. Naumov, G. I.; James, S. A.; Naumova, E. S.; Louis, E. J.; Roberts, I. N. Three new species in the Saccharomyces sensu stricto complex: Saccharomyces cariocanus, Saccharomyces kudriavzevii and Saccharomyces mikatae. Int. J. Syst. Evol. Microbiol. 2000, 50 Pt 5, 1931-1942, doi:10.1099/00207713-50-5-1931.

44. Hutzler, M.; Michel, M.; Kunz, O.; Kuusisto, T.; Magalhães, F.; Krogerus, K.; Gibson, B. Unique brewing-relevant properties of a strain of Saccharomyces jurei isolated from ash (Fraxinus excelsior). BioRxiv 2021, doi:10.1101/2021.01.11.426216. 
45. Erny, C.; Raoult, P.; Alais, A.; Butterlin, G.; Delobel, P.; Matei-Radoi, F.; Casaregola, S.; Legras, J. L. Ecological success of a group of Saccharomyces cerevisiae/Saccharomyces kudriavzevii hybrids in the northern european wine-making environment. Appl. Environ. Microbiol. 2012, 78, 3256-3265, doi:10.1128/AEM.06752-11.

46. Masneuf, I.; Hansen, J.; Groth, C.; Piskur, J.; Dubourdieu, D. New hybrids between Saccharomyces sensu stricto yeast species found among wine and cider production strains. Appl. Environ. Microbiol. 1998, 64, 3887-3892.

47. Groth, C.; Hansen, J.; Piskur, J. A natural chimeric yeast containing genetic material from three species. Int J Syst Bacteriol 1999, 49 Pt 4, 1933-1938, doi:10.1099/00207713-49-41933.

48. González, S. S.; Barrio, E.; Querol, A. Molecular characterization of new natural hybrids of Saccharomyces cerevisiae and S. kudriavzevii in brewing. Appl. Environ. Microbiol. 2008, 74, 2314-2320, doi:10.1128/AEM.01867-07.

49. Sampaio, J. P.; Gonçalves, P. Natural populations of Saccharomyces kudriavzevii in Portugal are associated with oak bark and are sympatric with $S$. cerevisiae and $S$. paradoxus. Appl. Environ. Microbiol. 2008, 74, 2144-2152, doi:10.1128/AEM.02396-07.

50. Orlic, S.; Redzepovic, S.; Jeromel, A.; Herjavec, S.; Iacumin, L. Influence of indigenous Saccharomyces paradoxus strains on Chardonnay wine fermentation aroma. Int. J. Food Sci. Tech. 2007, 42, 95-101, doi:10.1111/j.1365-2621.2006.01217.x.

51. Martini, A. V.; Martini, A. A proposal for correct nomenclature of the domesticated species of the genus Saccharomyces. In Biotechnology applications in beverage production; Cantarelli, C., Lanzarini, G., Eds.; Springer Netherlands: Dordrecht, 1989; pp. $1-16$.

52. Majdak, A.; Herjavec, S.; Orlic, S.; Redzepovic, S.; Mirosevic, N. Comparison of Wine Aroma Compounds Produced by Saccharomyces paradoxus and Saccharomyces cerevisiae Strains. Food Technol Biotechnol 2002, 40, 103-109.

53. Dunn, B.; Richter, C.; Kvitek, D. J.; Pugh, T.; Sherlock, G. Analysis of the Saccharomyces cerevisiae pan-genome reveals a pool of copy number variants distributed in diverse yeast strains from differing industrial environments. Genome Res. 2012, 22, 908-924, doi:10.1101/gr.130310.111.

54. Bellon, J. R.; Schmid, F.; Capone, D. L.; Dunn, B. L.; Chambers, P. J. Introducing a new breed of wine yeast: interspecific hybridisation between a commercial Saccharomyces cerevisiae wine yeast and Saccharomyces mikatae. PLoS One 2013, 8, e62053, doi:10.1371/journal.pone.0062053.

55. Bellon, J.; Schmidt, S.; Solomon, M. Case study: development of Saccharomyces cerevisiae $\times$ Saccharomyces mikatae wine yeast hybrids and their potential to deliver alternative wine styles . AWRI Tech. Rev. 2019, 241, 6-11. 
56. Naumova, E. S.; Naumov, G. I.; Masneuf-Pomarède, I.; Aigle, M.; Dubourdieu, D. Molecular genetic study of introgression between Saccharomyces bayanus and $S$. cerevisiae. Yeast 2005, 22, 1099-1115, doi:10.1002/yea.1298.

57. Fay, J. C.; Liu, P.; Ong, G. T.; Dunham, M. J.; Cromie, G. A.; Jeffery, E. W.; Ludlow, C. L.; Dudley, A. M. A polyploid admixed origin of beer yeasts derived from European and Asian wine populations. PLoS Biol. 2019, 17, e3000147, doi:10.1371/journal.pbio.3000147.

58. Almeida, P. M. C. de Microbe Domestication and the Identification of the Wild Genetic Stock of Wine Yeasts. Master thesis, Universidade Nova de Lisboa, 2016.

59. Nguyen, H.-V.; Gaillardin, C. Evolutionary relationships between the former species Saccharomyces uvarum and the hybrids Saccharomyces bayanus and Saccharomyces pastorianus; reinstatement of Saccharomyces uvarum (Beijerinck) as a distinct species. FEMS Yeast Res 2005, 5, 471-483, doi:10.1016/j.femsyr.2004.12.004.

60. Pérez-Torrado, R.; González, S. S.; Combina, M.; Barrio, E.; Querol, A. Molecular and enological characterization of a natural Saccharomyces uvarum and Saccharomyces cerevisiae hybrid. Int. J. Food Microbiol. 2015, 204, 101-110, doi:10.1016/j.ijfoodmicro.2015.03.012.

61. Januszek, M.; Satora, P.; Wajda, Ł.; Tarko, T. Saccharomyces bayanus Enhances Volatile Profile of Apple Brandies. Molecules 2020, 25, doi:10.3390/molecules25143127.

62. SAFENO ${ }^{\mathrm{TM}} \mathrm{HD}$ T18 • Fermentis Available online: https://fermentis.com/en/fermentationsolutions/you-create-wine/safoeno-hd-t18/ (accessed on Apr 6, 2021).

63. Lafontaine, S.; Caffrey, A.; Dailey, J.; Varnum, S.; Hale, A.; Eichler, B.; Dennenlöhr, J.; Schubert, C.; Knoke, L.; Lerno, L.; Dagan, L.; Schönberger, C.; Rettberg, N.; Heymann, H.; Ebeler, S. E. Evaluation of Variety, Maturity, and Farm on the Concentrations of Monoterpene Diglycosides and Hop Volatile/Nonvolatile Composition in Five Humulus lupulus Cultivars. J. Agric. Food Chem. 2021, doi:10.1021/acs.jafc.0c07146.

64. Takoi, K.; Koie, K.; Itoga, Y.; Katayama, Y.; Shimase, M.; Nakayama, Y.; Watari, J. Biotransformation of hop-derived monoterpene alcohols by lager yeast and their contribution to the flavor of hopped beer. J. Agric. Food Chem. 2010, 58, 5050-5058, doi:10.1021/jf1000524.

65. Bruner, J.; Marcus, A.; Fox, G. Dry-Hop Creep Potential of Various Saccharomyces Yeast Species and Strains. Fermentation 2021, 7, 66, doi:10.3390/fermentation7020066.

66. Schisler, D. O. Comparison of revised yeast counting methods. ASBCJ 1986, 44, 81-85, doi:10.1094/ASBCJ-44-0081.

67. Bamforth, C. W. Scientific Principles of Malting and Brewing; American Society of Brewing Chemists, Ed.; American Society of Brewing Chemists: St. Paul, MN, USA, 2006; p. 246. 
68. Lafontaine, S. R.; Shellhammer, T. H. Impact of static dry-hopping rate on the sensory and analytical profiles of beer. J. Inst. Brew. 2018, 124, 434-442, doi:10.1002/jib.517.

69. Hauser, D. G.; Simaeys, K. R. V.; Lafontaine, S. R.; Shellhammer, T. H. A Comparison of Single-Stage and Two-Stage Dry-Hopping Regimes. ASBCJ 2019, 77, 251-260, doi:10.1080/03610470.2019.1668230.

70. Boulton, C.; Quain, D. Brewing Yeast and Fermentation; 1st ed.; Wiley-Blackwell: Hoboken, NJ, USA, 2001; p. 656.

71. Technical Committee, A. Alcohol. In ASBC methods of analysis; American Society of Brewing Chemists: St. Paul, MN, USA, 2011.

72. Lawless, H. T.; Heymann, H. Sensory evaluation of food; 2nd ed.; Springer New York: New York, NY, USA, 2010; pp. 227-257.

73. Novel techniques in sensory characterization and consumer profiling; Varela, P., Ares, G., Eds.; CRC Press: Boca Raton, FL, USA, 2014; p. 408.

74. Moskowitz, H. R. Intensity scales for pure tastes and for taste mixtures. Percept. Psychophys. 1971, 9, 51-56, doi:10.3758/BF03213027.

75. Moskowitz, H. R.; Sidel, J. L. Magnitude and hedonic scales of food acceptability. J. Food Sci. 1971, 36, 677-680, doi:10.1111/j.1365-2621.1971.tb15160.x.

76. Jenkins, C. L.; Kennedy, A. I.; Hodgson, J. A.; Thurston, P.; Smart, K. A. Impact of serial repitching on lager brewing yeast quality. ASBCJ 2003, 61, 1-9, doi:10.1094/ASBCJ-610001.

77. Kalayu, G. Serial re-pitching: its effect on yeast physiology, fermentation performance, and product quality. Ann. Microbiol. 2019, 69, 787-796, doi:10.1007/s13213-019-01493-4.

78. Large, C. R. L.; Hanson, N. A.; Tsouris, A.; Abou Saada, O.; Koonthongkaew, J.; Toyokawa, Y.; Schmidlin, T.; Moreno-Habel, D. A.; McConnellogue, H.; Preiss, R.; Takagi, H.; Schacherer, J.; Dunham, M. J. Genomic stability and adaptation of beer brewing yeasts during serial repitching in the brewery. BioRxiv 2020, doi:10.1101/2020.06.26.166157.

79. Lee, Y.-J.; Choi, Y.-R.; Lee, S.-Y.; Park, J.-T.; Shim, J.-H.; Park, K.-H.; Kim, J.-W. Screening wild yeast strains for alcohol fermentation from various fruits. Mycobiology 2011, 39, 33-39, doi:10.4489/MYCO.2011.39.1.033.

80. Olodokun, O.; Cowley, T.; James, S.; Smart, K. A. Dry-hopping: the effects of temperature and hop variety on the bittering profiles and properties of resultant beers. Brewing Science 2017, 70, 187-196.

81. Kirkpatrick, K. R.; Shellhammer, T. H. A Cultivar-Based Screening of Hops for Dextrin Degrading Enzymatic Potential. ASBCJ 2018, 76, 247-256, doi:10.1080/03610470.2018.1546091. 
82. Kirkendall, J. A.; Mitchell, C. A.; Chadwick, L. R. The freshening power of centennial hops. ASBCJ 2018, 1-7, doi:10.1080/03610470.2018.1469081.

83. Bruner, J. R.; Williams, J.; Fox, G. P. Further Exploration of Hop Creep Variability with Humulus lupulus Cultivars and Proposed Method for Determination of Secondary Fermentation. MBAA TQ 2020, 57, doi:10.1094/TQ-57-3-1002-01.

84. Stokholm, A.; Lindsey N., R.; Shellhammer, T. H. Evaluating a benchtop fermentation method for estimating dextrin degradation by hops' diastatic enzymes during dry-hopping. Brewing Science 2020, 73, 140-148.

85. Maye, J. P.; Smith, R.; Leker, J. Humulinone formation in hops and hop pellets and its implications for dry hopped beers. MBAA TQ 2016, 53, 23-27, doi:10.1094/TQ-53-10227-01.

86. Hopsteiner | Hop Profiles - Centennial Available online: https://www.hopsteiner.com/variety-data-sheets/Centennial/ (accessed on Apr 12, 2021).

87. Mertens, S.; Steensels, J.; Gallone, B.; Souffriau, B.; Malcorps, P.; Verstrepen, K. J. Rapid Screening Method for Phenolic Off-Flavor (POF) Production in Yeast. ASBCJ 2017, 75, 318-323, doi:10.1094/ASBCJ-2017-4142-01. 